\title{
Linking Bioeconomy to Redevelopment in Contaminated Sites: Potentials and Enabling Factors
}

\author{
Fedra Francocci ${ }^{1 *}$, Fabio Trincardi ${ }^{2}$, Andrea Barbanti ${ }^{3}$, Massimo Zacchini ${ }^{4}$ and \\ Mario Sprovieri ${ }^{1}$
}

1 Institute of Anthropic Impacts and Sustainability in Marine Environment (IAS), National Research Council, Rome, Italy, 2 Department of Earth System Science and Environmental Technologies (DSSTTA), National Research Council, Rome, Italy, ${ }^{3}$ Institute of Marine Sciences (ISMAR), National Research Council, Venice, Italy, ${ }^{4}$ Research Institute on Terrestrial

Ecosystems (IRET), National Research Council, Rome, Italy

\section{OPEN ACCESS}

Edited by:

Raul Perez Lejano,

New York University, United States

Reviewed by:

Bing Xue,

Institute for Applied Ecology (CAS),

China

Kenneth R. McPherson,

United States Environmental Protection Agency (EPA),

United States

${ }^{*}$ Correspondence:

Fedra Francocci

fedra.francocci@ias.cnr.it

Specialty section:

This article was submitted to

Toxicology, Pollution and the

Environment

a section of the journa

Frontiers in Environmental Science

Received: 10 September 2019

Accepted: 29 July 2020

Published: 22 September 2020

Citation:

Francocci F, Trincardi F,

Barbanti A, Zacchini M and

Sprovieri M (2020) Linking

Bioeconomy to Redevelopment in Contaminated Sites: Potentials

and Enabling Factors.

Front. Environ. Sci. 8:144.

doi: 10.3389/fenvs.2020.00144
This article proposes a bioeconomy approach to the management of contaminated sites with the aim to identify actions for the development of a common policy framework for environmental protection and sustainable development. Among the policies addressing pollution on land and at sea, we identify four main gaps that hamper the implementation of measures for the prevention and management of contaminated sites from local to systemic scales. We introduce three concepts from bioeconomy-(i) value-chain, (ii) regional perspective, and (iii) multi-sector approach-that are potentially conducive to socio-economic and environmental improvement of degraded areas in Europe.

Keywords: bioeconomy, circular economy, bioremediation, pollution, nature-based solution, smart specialization

\section{INTRODUCTION}

The last 70 years of super-exponential growth of the world economy led to the exploitation of not-renewable resources and the increasing production of mismanaged waste (Steffen et al., 2015). In this context, land and coastal regions worldwide have been extremely under pressure coming from urbanization and the related growth of infrastructures and industries. The Mediterranean coastal areas, for example, witness the legacy of this economic growth with numerous refineries, chemical and steel plants, often decommissioned or in a phase of recasting, accompanied by high volumes of dangerous materials in extensive landfills and near-shore dumps. As a consequence, contamination caused by anthropic activities represents a major threat affecting terrestrial and marine ecosystems, and for this reason, such areas are monitored and occasionally recovered at the European, national, and local levels (Payá Pérez and Rodríguez Eugenio, 2017; Eea Report, 2019). However, the restoration and reintroduction of such areas into productive, and hopefully sustainable, value chains are difficult to achieve while management measures are fragmented and lack an integrated plan for remediation and development, from a local to a systemic level. In the context of a growing population, facing also global challenges like climate change, sea level rise and land/coastal ecosystem degradation, the interest in the use of renewable resources is growing, with the aim to catalyze the economic transformation and to implement more sustainable consuming strategies. 
With this aim, we propose a new approach to the management of contaminated sites, i.e., areas of environmental and ecosystem degradation and resource depletion with consequent socioeconomic loss, by applying bioeconomy principles to help overcome major limits and gaps that prevent the reintegration of these areas into productive chains. We discuss how this approach could drive the choice of restoration measures in contaminated areas, while producing value and jobs. The study (i) presents an analysis of policy and management measures undertaken at the local, regional, and country levels and of main existing gaps; (ii) discusses the added value of bioeconomy approaches to recover contaminated areas from an environmental, economic, and social point of view; and (iii) proposes an integrated concept of management of contaminated areas in a circular bioeconomy perspective for business operators and decision makers.

\section{OVERVIEW OF POLICY FRAMEWORK FOR PREVENTING AND MANAGING SOIL/COASTAL POLLUTION: MAJOR GAPS AND LIMITS}

The urgent need to reduce pollution across Europe and to maintain healthy soils and seas (water column and sea floor) is widely recognized, although this is a goal difficult to achieve because chemical substances, including heavy metals, persistent organic pollutants, and also emerging contaminants tend to persist in all environmental matrixes. Indeed, several classes of contaminants are widespread and still above the legal threshold levels in extensive portions of Europe's terrestrial and marine environments (Payá Pérez and Rodríguez Eugenio, 2017; Eea Report, 2019). Presently, contamination is mainly driven by increasing economic activity together with mismanaged waste storage and disposal practices, all leading to the dispersal of contaminants into soil, groundwater, and marine environments, from coastal to offshore regions (Payá Pérez and Rodríguez Eugenio, 2017; Eea Report, 2019). The main sources of these contaminants include inadequate and unsustainable agricultural and forestry practices, industrial activities, treated and untreated waste water, tourism, urban and industrial sprawl, shipping, port activities, aquaculture, fisheries, offshore oil exploitation, and consumption of fossil fuels (Payá Pérez and Rodríguez Eugenio, 2017; Eea Report, 2019). Based on the analysis of the JRC report on progress in management of contaminated sites (Payá Pérez and Rodríguez Eugenio, 2017) and the EEA report on contaminants in Europe's seas (Eea Report, 2019), we focus on existing policies and cross-policy approaches, identifying four potential gaps that should be considered for implementing a common framework and for progress in environmental protection and restoration actions.

\section{Spatial 'Separation' (Gap 1)}

Across European countries, the assessment and management of contaminated areas deal with policies that separately address marine and terrestrial environments. This existing approach is probably due to the specificity of features (from chemical and physical properties to the ecosystems structure and functioning) that distinguish each environmental compartment and consequently influence and drive management and remediation practices. Land and sea also differ in terms of anthropic uses, multiplicity of sectors, and activities with distinctive environmental and socioeconomic impacts. The "land or sea" approach intrinsically fails in linking causes to effects in an integrated framework that would rather lead to measures preventing further pollution through long-termoriented remediation strategies. In particular, transitional coastal areas, with their relevant anthropic impacts and specific and fragile ecosystems, suffer from the lack of integrated approaches to environment restoration and recovery.

\section{'Fragmented' Policies (Gap 2)}

The policy framework in use lacks a coordinated approach aimed at preventing and managing the contamination on land and sea. On land, the protection and sustainable use of soil is regulated by indirect measures (Com/2012/046, 2012) and includes policies addressing contamination sources (targeting industrial policies or chemicals directives) and specific actions dedicated to soil conservation or land use regulation. The existing framework of policy regulation primarily encompasses major compartments: waste management (Directive 2008/98/EC, 2008); landfill (Council Directive 1999/31/EC, 1999); wastewater and water resource protection (Directive 2000/60/EC, 2000); evaluation, authorization, and restriction of chemical industrial activities (Directive 2004/35/CE, 2004; Regulation (EC) No 1907/2006, 2006); nature protection and biodiversity conservation (Directive 2009/147/EC, 2009; COM/2011/244, 2011); nitrates and pesticides (Council Directive 91/676/EEC, 1991; Directive 2009/128/EC, 2009); sewage sludge (Council Directive 86/278/EEC, 1986); forestry strategy (COM 2013/659, 2013); climate change adaptation and mitigation (COM/2013/216, 2013); and energy (Directive 2009/28/EC, 2009). Remarkably, none of these regulations includes guidelines to systematically manage and specifically regulate soil contamination (FrelihLarsen et al., 2016). Moreover, the effectiveness of all those policy instruments depends on the implementation actions at the national/regional level with a potential consequent fragmentation in terms of measures/regulations adopted among - and withinmember states. In the marine compartment, instead, the need to substantially reduce pollution (both in coastal marine areas and offshore) is widely recognized, but specific remediation actions are difficult to achieve due to the heterogeneity of the environmental matrices and the lack of available technologies. Differently from soil, the comprehensive European Integrated Maritime Policy (COM 2007/575, 2007) aims to achieve coherence across the range of economic activities in the marine environment carried out by different marine sectors. The uses of marine resources should be constrained within sustainable limits, as stated by the 'Blue Growth Directive' (SWD 2017/128, 2017) and need to be harmonized as outlined by the Maritime Spatial Planning Directive (Directive 2014/89/EU, 2014). In this context, the Marine Strategy Framework Directive (MSFD) (Directive 2008/56/EC, 2008) sets the standards conducive to the achievement, or preservation, of the good environmental 
status through a sustainable use of marine ecosystems and provides the overarching compliance criteria to adopt in conducting economic activities (e.g., Borja et al., 2017). The main pressures affecting European seas have been identified by different reports (UNEP, 2018; Eea Report, 2019) and are considered as central in the MSFD (Directive 92/43/EEC, 1992; Directive 2000/60/EC, 2000).

\section{Lack of a Common Framework for Local and Regional Development and Funding (Gap 3)}

Financing is key among the indirect measures aimed at addressing the problem of remediation of polluted sites. More than $42 \%$ of the total costs for remediation come from public budgets (only referring to soil remediation; Payá Pérez and Rodríguez Eugenio, 2017) with an urgent need to include local and private stakeholders in the management of contaminated sites to find productive and inclusive solutions. Financing instruments and thematic strategies useful for supporting remediation and risk reduction are identified in the JRC report (Payá Pérez and Rodríguez Eugenio, 2017) and include instruments, such as H2020 and Life Programme, that may contribute to advancing environmental protection on land and at sea through the promotion and financing of relevant research and innovation. However, a cross-policy analysis reveals the lack of a dedicated strategy for attracting private funding as well as a robust framework for their implementation. Even if the European Regional Development Funds (ERFD) and Cohesion Fund (CF) are mentioned among the relevant indirect measures (Payá Pérez and Rodríguez Eugenio, 2017) no further action defining a medium- to long-term plan for development is clearly defined both at regional or European level, thus reducing the effective adoption of specific and concrete measures. This weakness reflects the lack of a strategic economic plan of development based on a new use of contaminated areas, thus limiting the interest of private stakeholders and investors.

\section{Uncertain Potential for Economic Outlooks (Gap 4)}

A productive use of contaminated areas mentioned by the crossreport analysis suggests further uses of biomass produced on contaminated soils as biofuel (Directive 2009/28/EC, 2009) for its positive impact in soil protection. No other reference is, however, made to additional products or services provided, among which the ecosystem services, even though their value is not easily quantifiable. Furthermore, the policies that cover aspects related to industrial production are described for their role in preventing pollution arising from industrial activities (Directive 2010/75/EU, 2010) while strategies for remediation purposes or sustainable development of industrial processes are not indicated. Strategies of circular economy are mentioned in the EEA report (Eea Report, 2019) but only in relation to the prevention of plastic pollution at sea and reduction of soil contamination (FrelihLarsen et al., 2016). This analysis reveals that the approaches commonly undertaken at the regional, national, and European scale focus on risk assessment, mitigation, and recovery from pollutants but lack a broader strategic plan for the long-term reincorporation of contaminated areas into productive and sustainable economic activities.

\section{A NEW APPROACH TO THE MANAGEMENT OF CONTAMINATED AREAS THROUGH BIOECONOMY}

The goal of bioeconomy is to improve sustainably the productivity and quality of products of economic sectors by creating longer and more locally routed value chains, where the actions of public and private stakeholders integrate across all major sectors (BIT II, 2019). A key aspect in bioeconomy is exploiting terrestrial/marine biodiversity, ecosystem services, and circularity to regenerate abandoned marginal lands and former industrial sites.

We here propose a new approach to the management of contaminated areas to fill the gaps identified in the previous section. To this end, we moved from a sectorial solutionoriented approach to a (sustainable) development-oriented approach primary considering the modern European Economic strategies. Among these strategies, bioeconomy offers key principles to advance in this direction. Bioeconomy, often referred also as bio-based economy, involves the sustainable use of renewable biological resources, biological waste and residual material to produce food, energy, and industrial goods. Bioeconomy is driving the transition toward a more sustainable economy by addressing major global challenges (including food security, climate change, resource scarcity) and ultimately reconciling economic activity within the planetary boundaries (Lewandowski, 2018). Bioeconomy exploits biological (biobased) resources through efficient production and conversion technologies providing environmental and economic services and promoting the transition to a more sustainable society. We thus propose as a new model the Integrated Bioeconomy Approach to the Management of Contaminated Areas (hereinafter Integrated Bioeconomy Approach) that combines (i) the environmental restoration through nature-based solution and (ii) the establishment of productive bio-based value chains (described in section "Bioeconomy as a successful 'horizontal strategy' to build integrated policies for contaminated site management"), specifically focused on socio-economic development of contaminated areas. This approach is expected to break through some major blocks in the application of remediation solutions and to overcome the current limits in the management of contaminated areas.

In Table 1 we report the four gaps described in the previous section, together with proposed specific activities that result from the application of the Integrated Bioeconomy Approach. These activities are particularly oriented to implement specific EU policy trajectories and to achieve integrated actions for preventing further pollution and managing contaminated areas by using modern approaches of environment restoration and socioeconomic valorization.

Synthetically, the spatial gap shows the limits in addressing the management and remediation of contaminated sites by referring 
TABLE 1 | Gaps in EU Policy framework and suggested actions.

GAP 1 Description

Spatial separation

Policies related to the prevention and management of contaminated sites are commonly overseen separately with respect to specific areas of interest on land and offshore. The lack of an integrated approach mainly affects the coastal area that, for its hybrid nature, should be managed by taking into account both land and offshore related features. The spatial approach prevents from considering the multiplicity of activities, factors, and sectors that are recognized to be responsible for contamination.

\section{Suggested Action 1}

Integration of policies considering the land-sea continuum

\section{Expected outcome}

An integrated approach to land and sea related policies will result in: better addressing land/sea interaction related features; improvement of coastal management; consequent broadening of the analysis of economic sectors responsible for contamination; and development of a comprehensive framework of policy references.

\section{GAP 2}

Fragmented policies

\section{Suggested Action 2}

Building an integrated and common policy framework

\section{GAP 3}

Lack of a common framework for basin or regional development strategies

\section{Suggested Action 3}

Prioritization of domains, areas and economic activities

\section{Description}

The fragmentation in the measures adopted among - and within-member states influences their effectiveness.

\section{Expected outcome}

Allowing crosscutting policy building; facilitating the dissemination and increase the adoption of management measures for contaminated sites from local to systemic level

\section{Description}

Despite the link with the Cohesion Fund (CF) or European Regional Development Fund (ERDF) suggested in the case of soil management (JRC), the lack of a framework supporting regional or macro-regional development opportunities limits the implementation plans for the management of contaminated sites and hinders the development of potentially productive and inclusive solutions.

\section{Expected outcome} unique opportunities for development and growth; facilitating the exchange of good practices and addressing
Prioritization of specific assets and resources related to the prevention and management of contaminated sites, with measures for managing contaminated site; promoting multi-stakeholder engagement for contaminated site's solutions; favoring the integration of policies from local to regional and macro-regional dimensions; support effective measures to favor private Research and Innovation investments

\section{GAP 4}

\section{Description}

Uncertain potential economic outlooks

Value chains fully implemented and specifically linked to economic sectors and market of reference; lack of a pilot or good practice in business models construction

\section{Suggested Action 4}

Identification of development scenarios promoting business and investments

\section{Expected outcome}

Developing bio-based sustainable value chains and services in degraded areas; bringing private and public investments in establishing value chains; fostering new integrated business models in the bioeconomy; opening multiple possibilities among different sectors and targets to the land or marine environment, separately. Integration of policy across diverse environmental compartments is proposed as a tool to better address cross-cutting issues and by building on the specificity of each compartment in terms of technical features and socio-economical attributes (suggested action 1). Building an integrated policy framework (suggested action 2) would overcome the fragmentation of policies (gap 2) by setting the framework for the future development of mitigation measures based on cross-sectorial policy and multi-stakeholder analysis. This approach looks at incorporating in the remediation and management policies those aspects related to the productive use of such areas and other direct/indirect policies relevant for their implementation from local to systemic level. "Prioritization of domains, areas and economic activities related to management of contaminated sites" (suggested action 3) would address the lack of a common framework for local or regional development strategies (gap 3). To reach this goal, a broad stakeholder analysis can influence policymakers to design suitable strategies accordingly. Strategies for regional development and European economic policies are also crucial to push efficiently integrated policies (for remediation) from local to systemic level. In this regard, targeted pilot actions-ranging from the technical features to the integrated policy design addressing the socioeconomic and environmental sustainability as a wholerepresent the key to unlock the local to systemic transition by providing their feasibility in terms of replication capacity, and transferability potential. Lastly, the lack of a well-defined economic potential (gap 4) can be overcome by identifying strategic areas for business development and investments (expected outcome/suggested action 4). The use of regenerative, sustainable, and bio-based value chains or services applied to the management of contaminated sites would set up new integrated business models, thus opening possibilities for multiple market sectors and job creation at the local level. Pilot actions are 
necessary to demonstrate the economical sustainability of the models but also to demonstrate that the model is transferable to other Areas/Regions/Countries characterized by a diverse set of assets. The business model has to be adapted to local peculiarities in terms of socio economical aspects, environmental features, level of contamination, but also to the maturity of those enablers that are responsible for the implementation of the identified business models (taking into account technological, infrastructure, and logistic capabilities).

The proposed actions demand a highly innovative 'socioeconomic ecosystem' and a policy framework centered on the key concept of sustainability through the adoption of adaptable, scalable and transferable business models. Notably, the suggested actions also reflect an approach focused on the complexity of the management of contaminated areas as an integrated system, linking causes and effects, as well as connecting different sectors and application fields. In the next paragraph, we discuss three specific aspects of the bioeconomy (hereinafter indicated lines) that are responsible for the Integrated Bioeconomy Approach effectiveness.

\section{Bioeconomy as a Successful 'Horizontal Strategy' to Build Integrated Policies for Contaminated Site Management}

The European Bioeconomy Strategy, launched and adopted in 2012, addresses the production of renewable biological resources and their conversion into value-added products,

\begin{tabular}{|c|c|}
\hline 口Bioeconomy specific & 口Sector supply \\
\hline $\begin{array}{l}\text { Commission communication } \\
\text { 'Innovating for sustainable } \\
\text { growth: a bioeconomy for } \\
\text { Europe' }\end{array}$ & $\begin{array}{l}\text { Agricultural } \\
\text { Forest-based sector } \\
\text { Fisheries, Aquaculture and algae }\end{array}$ \\
\hline घSector using biomass & 口Cross-cutting policies \\
\hline $\begin{array}{l}\text { Food and nutrition security } \\
\text { Energy } \\
\text { Bio-based Industries }\end{array}$ & $\begin{array}{l}\text { Environmental protection and } \\
\text { Climate Change } \\
\text { Circular economy - Waste } \\
\text { Regional policies - Smart } \\
\text { specialisation } \\
\text { Research and Innovation } \\
\text { Industrial policy }\end{array}$ \\
\hline \multicolumn{2}{|c|}{$\begin{array}{l}\text { FIGURE } 1 \text { | Bioeconomy-related policies and strategies. Description of } \\
\text { relevant policies and strategies for the bioeconomy. Based on A sustainable } \\
\text { bioeconomy for Europe: strengthening the connection between economy, } \\
\text { society and the environment (Updated Bioeconomy Strategy, 2018). }\end{array}$} \\
\hline
\end{tabular}

including food, feed, bio-based products, and bioenergy. By definition, "bioeconomy covers all sectors and systems that rely on biological resources (animals, plants, micro-organisms and derived biomass, including organic waste), their functions, and principles. It includes and interlinks: land and marine ecosystems and the services they provide; all primary production sectors that use and produce biological resources (agriculture, forestry, fisheries, and aquaculture); and all economic and industrial sectors that use biological resources and processes to produce food, feed, bio-based products, energy and services" (Innovating for Sustainable Growth: A Bioeconomy for Europe, 2012). From its first release in 2012, the Strategy has been updated in 2018 in line with European priorities (State of the Union, 2018) with the aim to strengthen the connections among economy, society, and the environment. Since the first release, the bioeconomy strategy proposed a comprehensive approach to address specific deteriorations that our planet is facing (e.g., loss in biodiversity and environmental resources, energy, food supply). The updated European Bioeconomy Strategy (Updated Bioeconomy Strategy, 2018) better focuses on actions to accelerate the adoption of a sustainable European bioeconomy plan and to maximize the impact on the 2030 Agenda, its Sustainable Development Goals (SDGs), and the Paris Agreement. Now the strategy looks at circularity as an economy process that provides multiple valuecreation. This approach would allow a substantial change from the consumption of finite resources (Growth within, 2015) and accelerate the transition toward a circular, carbon-neutral economy in the framework of the three axes of renewed Industrial Policy Strategy (COM/2017/0479, 2017, final), Circular Economy Action Plan (COM/2019/190, 2019), and Accelerating Clean Energy Innovation (COM 2016/0763, 2016). This updated strategy cuts across several sectors and allows synergies that favor industrial symbiosis. The strategy refers, among others, to innovative policies impacting production routes (supply chains), use of bioresources (such as biomass), ecosystem protection, and smart specialization as reported in Figure 1. No specific EU bioeconomy legislation exists but rather an ensemble of sectorial legislation developed in a common framework.

With this in mind, we propose three specific lines of actions for the remediation/recovery and development of contaminated sites. These actions are expected to provide specific instruments to overcome the above-identified gaps and to support the development of a new integrated management plan of contaminated areas.

\section{Line 1: Generating Value Chains and Engaging Stakeholders: Potentials and Main Obstacles}

Bioeconomy has a positive potential impact on the recovery of contaminated sites as indicated by two specific actions in the updated EU Bioeconomy Strategy (namely Action 1.6 and Action 2.2), hereinafter described (Updated Bioeconomy Strategy, 2018). Applying circular-bioeconomy principles to soft biological remediation techniques (bioremediation) provides a cost-effective solution for the rehabilitation of degraded areas and would potentially create an economy that is restorative and 
regenerative. This approach is based on the establishment of bio-based value chains, a set of interlinked activities performed to deliver products/services for the market by adding value to biological bulk material (feedstock) (Lokesh et al., 2018). The H2020 Programme (For a better innovation support to SMEs, 2019) defines an industrial value chain as "the stages of value creation by enterprises and other organizations as part of the process of designing and delivering goods and services for their users." The bioeconomy represents a large potential for the development of new value chains from renewable biological materials such as bio-based products from lignocellulose, microalgae for the production of food and feed, including the conversion of organic waste into valuable products. Innovation may result from new combinations along and across existing value chains or by an innovative technology or process brought from one sector into another resulting in a disruptive effect (SuperBIO, 2016-2019). This valorization process incorporates a large number of different actors and can positively contribute to socio-economic, environmental, and technological advances (Lokesh et al., 2018), through the addition of value and building new cross-border and cross-sectorial collaboration, innovation, and entrepreneurship. A schematic description of the key elements involved in the establishment of a bio-based value chain is shown in Figure 2 as a reference example.

However, estimates of jobs and growth created by the bioremediation actions in bioeconomy are still lacking and mirror the lack of a value chain on contaminated areas because of unclear market reference and applications. The potential intrinsic value of bioresources impacts on the production of goods or services also in contaminated areas. The development of sustainable products and processes from contaminated areas requires an interdisciplinary systemic analysis of entire value chains from feedstock, processing, and conversion, up to the levels of manufacture and marketing of products. The main bottlenecks for process implementation and value chain creation include the technological issues related to scientific knowledge on biomass exploitation and industrial scale-up and the need of a clear definition of the proper policy landscape building. For this reason, the engagement of key stakeholders across all elementary value chain fragments would represent a priority action to unlock the potential and thus implement the entire process combining the effects of research knowledge, industrial interest, social acceptance, and policy orientation. A number of research and pilot industrial projects already demonstrated

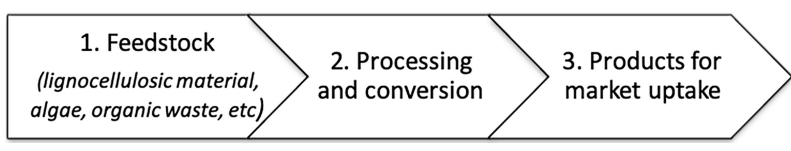

FIGURE 2 | Simplified scheme of a bio-based value chain. The figure represents a non-exhaustive description of the elements that are involved in the establishment of a bio-based value chain. Blocks indicate, respectively: sustainable biomass production and collection (block 1), breakthrough technology of processes and their conversion routes (block 2), and production of innovative added value products to the market (block 3 ). that nature-based solutions are effective in restoring ecosystems from complex soil and water pollution (Fiorentino et al., 2010; Bianconi et al., 2011; Dubois and Gomez San Juan, 2016; Pietrini et al., 2018); among these, phytotechnologies and bioremediation rely on the ability of specific plants, fungi, or bacteria to degrade, stabilize, or remove pollutants in specific environmental compartments. Nonetheless, the entire value chain has not yet been designed on a large scale and reference markets or economically viable scenarios have still to be set up. Indeed, so far the biomass produced as a result of the phyto- and bioremediation interventions is generally treated as a waste. This approach represents a loss in terms of exploitable feedstock, costs for waste disposal, and sustainability of the entire process with a consequent negative effect on the application of the technology on a larger scale. The Action 1.6 of the Bioeconomy Strategy "Strengthen and scale-up the bio-based sectors, unlock investments and markets" is expected to contribute to the development of further bioremediation methods through their integration with dedicated markets. There is a wide variety of knowledge and technological expertise needed for bioeconomy-related activities, and the challenge to apply bioeconomy principles to contaminated sites includes research- and industry-driven aspects and demands innovation in bioeconomy value chains. As an example, there are still relevant gaps of knowledge on the effects of the presence of contaminants on biomass quality and conversion/valorization potential (Bianconi et al., 2011; Pietrini et al., 2019). Preliminary studies on processes for biomass treatment coming from phytoremediation activities and consequent valorization into a biorefinery perspective also using microorganism (Sotenko et al., 2017) have been undertaken with the aim to pave the way for successful commercialization of bio-based products and services from contaminated areas. On the other hand, in the marine compartment, some solutions have been explored to convert bioresources such as microalgae into valuable products (e.g., fertilizers) from waste (SABANA Project, 20162021) as well as promoting the entry of new technologies to use bioremediator organism for the restoration of polluted environments (REMEDIA Project, 2017-2021). Nonetheless, despite the specific context of bioeconomy application, the capacity to create value chains in a framework of contaminated sites varies according to the local assets, to the availability of specific bioresources, and to the presence of research infrastructure or biorefineries (Spatial Foresight, 2017). Among the key factors conducive to the development of a bioeconomy plan, the capacity to engage the actors from multiple domains is the primary enabling factor to set up new bio-based value chains (BioSTEP Consortium, 2017) and scale up processes. In this direction, a number of specific $\mathrm{H} 2020$ projects have been funded to promote multi-actor dialogue and multistakeholder co-creation of research, innovation, development, and political context in the bio-based economy (BIOVOICES Project, 2018-2020). Therefore, the dissemination of good practices for multi-stakeholder and cross-sectorial collaboration appears crucial, and examples of multi-stakeholder collaboration in the frame of European projects are numerous (Hasenheit et al., 2016). Also, the engagement of industrial actors is 
necessary for reaching the technological maturity across the value chain segments in the bio-based sector and to bring the value chain closer to the market. At European level, the Bio-Based Industries Joint Undertaking (BBI JU) Public-Private Partnership promotes a strong European bio-based industrial sector developing new biorefining technologies to sustainably transform renewable natural resources into bio-based products, materials, and fuels. As an example, the GRACE project demonstrated large-scale Miscanthus and hemp production on contaminated/degraded soil with the aim to secure the supply of sustainably produced raw materials for the growing European Bioeconomy (GRACE Project, 2017-2022).

\section{Line 2: Stimulating a Regional Perspective Toward Smart Specialization}

The bioeconomy strategy (Updated Bioeconomy Strategy, 2018) calls Member States and regions to boost sustainable bioeconomies through their Research and Innovation Strategies for Smart Specialization (RIS3). Pilot actions to support local bioeconomy development (at rural, coastal, and urban level) via Commission instruments and programs are available, and a number of European regions have already included bioeconomyrelated priorities (Spatial Foresight, 2017) in their mid-term strategy plans. This reflects the overarching goal of the European Bioeconomy Strategy to deploy bioeconomy across Europe acting as a vehicle for inclusive and sustainable growth at the local level. The targets for local development are the member state territories, such as regions, rural areas, cities, and coastal areas. The main goal of this bioeconomy framework is fostering local developments in the EU regions and cities while addressing sustainability targets. Once associated to the bioeconomy development of areas of environmental risk, tailored focused actions could reasonably boost the potential of innovation associated to supporting emerging sustainable valuechains and ecosystem services. This would in turn result in promoting sustainable and regenerative economies preventing further pollution associated to non-circular industrial activities and realizing remediation solutions. As an example, in Italy, a ministerial decree (D.P.C.M. May 19, 2005) declared the state of socio-economic and environmental emergency in the catchment of river Sacco after the detection of concentrations of betahexachlorocyclohexane $(\beta-\mathrm{HCH})$ above the limit level of $0.003 \mathrm{mg} / \mathrm{kg}$ in a sample of milk from a farm located in the municipality of Gavignano (RM). The perimeter of the contaminated area (Site of National Interest - SIN) was later enlarged to cover over 8,000 hectares included in 19 municipalities between the Provinces of Rome and Frosinone, where several industrial clusters are located. Since 2012 bioremediation approaches have been tested both in lab and pilot scale (Bianconi et al., 2011; Pietrini et al., 2019) with the double aim to remediate from contamination and turn the system into a sustainable value chain. Despite this serious situation, no political frameworks have been developed in the long term in the Region. This reflects the limits previously discussed (mostly technological showing the low maturity of funding for the bio-based sector, at that time) and the fragmentation of actions at the policy level that lacked measures to sustain the implementation of the actions in the medium to long term. Recently, on 7 March 2019, Lazio Region and the Ministry of the Environment and Land and Sea Protection signed a memorandum of understanding anticipating major financing for the SIN of the Sacco Valley that mainly looks at the characterization of the whole territory and at securing most critical areas. This action is key in sustaining the process of remediation of contaminated areas but needs to be implemented with measures able to build frameworks (from pilot building, value chain creation, etc.) to assure the long-term stability of the process. In the last few years, a number of actions emerged with the aim to test economic value chains at the local level from enterprises, associations, and research bodies supported by municipalities or by generic funding tools (as for example the Rural Development Program of Lazio Region, REG UE N. 1305/2013, 2013) without coordination or strategic alignment. So far, the increasing interest at the stakeholder level in the region has not been supported by specific funding at local scale, capable to demonstrate the full value chain within a general policy framework, targeting the economic and environmental rehabilitation of the territory in a whole bioeconomy perspective. Indeed, the updated strategy has recognized the remediation of contaminated sites in relation to the development of local bioeconomies within the 2.2 Action "Pilot actions to support local bioeconomy development (rural, coastal, urban) Point iii: 'Develop urban bioeconomies through piloting circular bioeconomy cities through Horizon Europe." Thus, the management of contaminated sites can be seen as a potential effective driver for local bioeconomy development. The Lazio Region included among the drivers in its RIS 3 the bioeconomy challenges and specifically referred to the role of sustainable and competitive bio-based industries. This alignment would help, once the barriers for implementation at local scale are identified, the setting of a framework between (i) regional development strategies, (ii) bioeconomy strategies, and (iii) management policies for contaminated sites with the result to fully unlock its potential in a perspective of regional development of a new smart specialization field in synergy with environment and society.

\section{Line 3: Multi-Sectoral Approach Across the Land-Sea Transition}

The ocean, including coastal regions, represents a new economic frontier, covering more than two-thirds of the Earth's surface, spanning an increasingly diverse range of activities directed to exploit biological and abiotic resources and space (for traffic, tourism, cable/pipeline connections, energy or aquaculture platforms and waste disposal). The ocean will play a key role in the next decade, particularly in scenarios of accelerated exploitation to fuel a blue great acceleration (Jouffray et al., 2020). Coastal areas present diverse criticalities, ranging from those derived from the extreme effects of climate change to those induced by rapidly increasing anthropic sprawling 
witnessed in Europe by the presence of half the population within $50 \mathrm{~km}$ from the coast and substantially increasing during touristic seasons (Collet and Engelbert, 2017). The coastal zone marks the border and may potentially represent a link, between land-based economies and the oceans but also the springboard to the offshore economy. Particular attention is dedicated to coastal development, boosted through the use of sea basin strategies and through dedicated strategic research and innovation agenda such as the ones for the Mediterranean (BLUEMED Initiative), the Black Sea, the Atlantic, and the Baltic. The aim to unlock the potential of the Blue Bioeconomy is a common objective of such strategies and agenda, in line with the "food security, sustainable agriculture and forestry, marine and maritime, and inland water research and the bioeconomy societal challenge" (Horizon 2020 Work Programme 2018-2020, 2020). The bioeconomy strategy specifically promotes local blue bioeconomies for the expected effect in generating actions addressing, among others, the issue of pollution at sea (Updated Bioeconomy Strategy, 2018). Some EU Member States and regions have R\&I priorities for their smart specialization in the field of blue bioeconomy that mainly refer to water bio-resources across the coastal zone. Even if the blue bioeconomy specialization pattern is present across European regions and countries, the bioeconomy potential is not fully applied and exploited to marine/coastal resources. The existing policy, if properly implemented, may help the management and remediation of complex contaminated sites that appear unfortunately widespread in the coastal area, in a policy framework that would possibly overcome the spatial separation (gap 1) and maximize the valorization of the overall environment by connecting multiple sectors (gap 2). Bioeconomy is leading European economies and Member States are developing strategies accordingly to valorize their resources (Spatial Foresight, 2017; Ronzon and M'Barek, 2018). At the regional level, the actions are mainly driven by the availability of natural resources and cultural heritage, accompanied by a motivated research environment, an established primary value chain, and a developed industrial biotech sector (Spatial Foresight, 2017). Most strategies combine several thematic focus areas and develop interconnections according to their internal or external drivers (Spatial Foresight, 2017). This aspect would favor the adaptability of business models and management approaches across multiple economic sectors and regional policy contexts. Therefore, rather than just planning the safety and recovery of a contaminated area, a targeted plan for management and valorization should include the analysis of all possible uses of that area. Business solution should take into account both risks and benefits in a whole environmental and socio-economic perspective of a region and should look at each segment of the bio-based value chain as a possibility to valorize cross-sectorial synergies. As demonstrated by the project SABANA (SABANA Project, 20162021), an interlink between multiple sectors as agriculture, aquaculture, and waste management is possible within a bioeconomy framework that targets the sustainable management of both marine and terrestrial environments. This approach is based on the development of an integrated microalgae-based biorefinery for the production of biostimulants, biopesticides, and feed additives, together with biofertilizers and aquafeed, using marine water and nutrients from wastewaters. The adoption of a bioeconomy-based approach would lead to solutions able to catch the peculiarity of each scenario and to valorize the drivers present in such a region even if apparently far from each other, to promote a new value chain that would potentially open new and multiple markets. This approach may rapidly lead to an enrichment of the portfolio of activities in a given coastal region, adding, for instance, advanced industrial activities to tourism or fisheries. Bioeconomy should support nature-based solutions in coastal areas offering new opportunities to local economies and also supporting the definition of new solutions for environmental recovery in a circular economy perspective.

In line with actions aimed at preventing pollution and/or managing contaminated areas (analysis of directives/regulations/strategies as shown in sections "Overview of policy framework for preventing and managing soil/coastal pollution: major gaps and limits" and "Bioeconomy as a successful 'horizontal strategy' to build integrated policies for contaminated site management"), the bioeconomy strategy provides significant added value in safeguarding resources by (i) promoting sustainable business models (value chains and stakeholders engagement), (ii) fostering principles of sustainability and circularity (multisectoral approaches of the bioeconomy strategy), and (iii) designing a strategic integrated perspective (defining a regional approach to development). Bastioli (2019) highlighted how the bioeconomy transition should be played on interdisciplinary and interconnected local projects and on our capacity of inclusion. It is therefore urgent to develop guidelines for a bioeconomy-based, integrated policy framework, from a local to a systemic level, to exploit the full bioeconomy potential also in environmentally degraded and economically depressed areas, founded on a sustainable use of renewable biological resources. Like this, the application of the Integrated Bioeconomy Approach will ultimately result in a new inclusive management of polluted terrestrial and aquatic ecosystems through a harmonized framework of policies with high socio-economic and environmental impact.

\section{DESIGN OF AN INTEGRATED CONCEPT FOR MANAGEMENT: TRANSITION TO ECONOMICALLY VIABLE SUSTAINABILITY FROM A LOCAL TO SYSTEMIC SCALE}

As already mentioned, innovative technologies and approaches to the management of contaminated environments are now available (Payá Pérez and Rodríguez Eugenio, 2017; Eea Report, 2019) with opportunities for remediation through biologicalbased technologies (natural based solutions, phytotechnologies, etc.), which guarantee sustainable and smart solutions (Lord et al., 2008; Regional Biotechnology, 2011; COM/2017/0479, 
2017). Nevertheless, the policy framework at the European, national, and regional levels on the management of risk areas and soil and water/sea protection never refers to circular bioeconomy as an instrument of direct or indirect prevention, mitigation, or remediation. Also, bioeconomy strategies do not mention the existing regulatory obstacles and seldom refer to the drivers associated to contaminated biomass exploitation. This regulatory gap represents a limit to the use of renewable bioresources both for remediation and for an economic perspective of contaminated areas. This gap reflects nonexhaustive scientific and methodological knowledge as well as the lack of potential actions supporting the implementation and spreading of good practices. The inclusion of the three abovedescribed lines of actions oriented to environmental recovery would result in a crosscutting approach able to favor the policy evolution at:

- multiple complementary scales (local, regional, national, European).

- cross-sectorial levels (agriculture production, waste management, industrial manufacture, etc.).
- integrated spatial levels on land (rural, urban, transitional zone) and their impact on marine coastal and offshore areas.

Figure 3 summarizes how to design a comprehensive strategy and promote sustainable and inclusive roadmaps for sustainable solutions based on research and innovation driving business model development. The overall idea, reflecting also what was discussed in the final report of the High-Level Panel of the European Decarbonisation Pathways Initiative (Final Report, 2019), is that the new trend for implementation challenges of this general transition should be based on the combination of credible policies and their integration with solid markets. Thus, to overarch strong policy guidance, quantitative models should support the selection of policy targets for restoration activities. Consequently, the environmental benefits and economic potentials derived from the application of bioeconomy principles to contaminated areas, described in this paper, should be incorporated and integrated in appropriate models to drive the policy process in the medium and long term and at multiple space-scale. Costanza et al. (2017) highlights

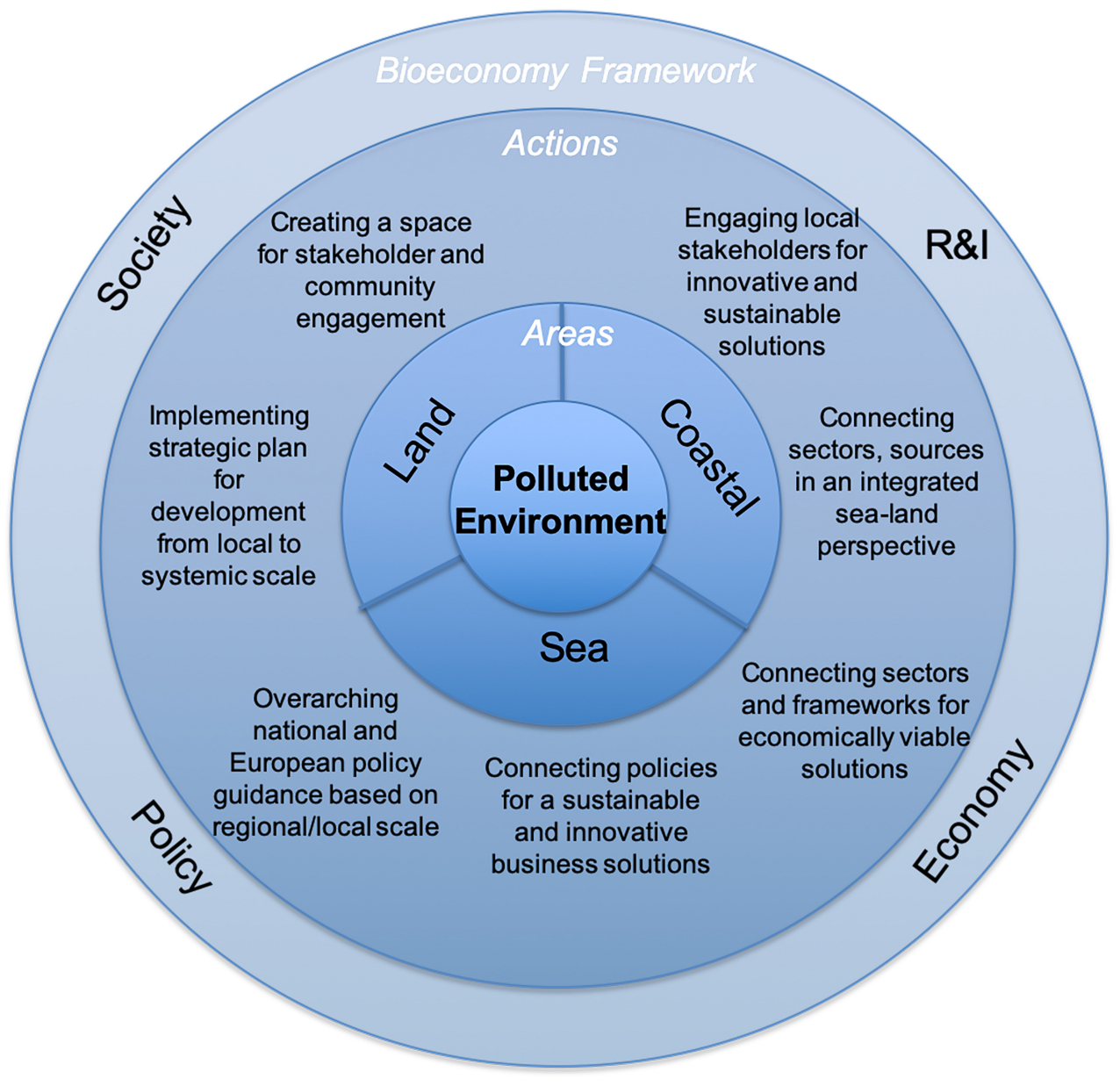

FIGURE 3 | Integrated concept for the management of contaminated areas in a circular bioeconomy perspective. The proposed conceptual model highlights areas, actions, and framework that would potentially contribute to the design of a comprehensive strategy of the polluted environment. 
the crucial importance, in the process of integrating ecosystem services and natural capital into mainstream economic policy, that the process be orchestrated to allow the wider dialogue and participation of actors. Building a comprehensive model including the bioeconomy stakeholder ecosystem would elicit and successfully exploit such process by taking into account the complexity of technological, economic, environmental, and social aspects. Indeed the integration of environmental and economic models for development is in line with the European Green Deal strategy's aim that looks at the transition to a prosperous society as beneficial for the EU economy, society, and natural environment. This includes the up-scaling restoration efforts for damaged ecosystems at sea and on land with the final aim to positively impact biodiversity and deliver a wide range of ecosystem services (COM 2019/640, 2019).

Integration from local to systemic approach should be encouraged with the perspective also to align policies. As suggested in the report on 'Regional Biotechnology-Establishing methodology and performance indicators for assessing biocluster and bio-regions relevant to the KBBE area' (Regional Biotechnology, 2011), among the success factors in bio-regions, the high level of awareness was instrumental for bringing bioeconomy on national and EU agendas. Locally, building multiple value chains based on remediation of contaminated areas would positively influence the allocation of resources and the attention of regional policy makers and politicians from local to systemic scale. If the design of national/regional research and innovation strategies for smart specialization would clearly take into account bioeconomy drivers associated to the management of contaminated areas, an integrated approach would become possible across all regions. Consequently, the European Structural and Investment Funds (ESIF), supporting the economic development across all EU countries, would unlock the potential of contaminated areas and allow a better harmonization of the implementation of diverse interventions. If the adoption of the bioeconomy takes place at multiple levels, taking into account existing productions, industrial ecosystems and policy-support systems related to both soil/water/sea protection and management of risk areas, then the political framework would evolve in line with the changing demands of a centralized, circular and regenerative model of production. In this view, a recent measure of the Italian Ministry of Environment (Decree 46/19, 2019) strongly directs the reclamation of agricultural areas toward the bio/phytoremediation technology by also envisaging the exploitation toward an economic perspective. This is a positive and promising policy action that goes in the direction of coupling the management of contaminated areas to a sustainable economic framework. This action should be integrated and sustained by adequate business models tools and frameworks for their implementation, including targeted policies addressing the controversial issue of the exploitation of resulting biomass/waste, together with dedicated financial measures and regional support from pilot to industrial scale, to be effective and to act as a model for similar actions across Europe.

The process of implementation of SDGs at the regional level may represent an enabling condition to test and demonstrate the integrated policy approach to contaminated area management toward a bioeconomic perspective. Local and regional authorities, together with local civil society, play an important role in implementing the Agenda 2030 by catalyzing EU financial and policy instruments to foster innovation and boost investments in transformative communitybased services supporting the achievement of the SDGs (United Nations, 2015). In this context, the European Commission should consider the territorial dimension of relevant policies in particular when they bring, and this is the case, socio-economic value. In 2019, The Ministry of the Environment and Land and Sea Protection of Italy launched a National call for proposals (Bando SNSVS 2, 2019) to promote research projects supporting the implementation of the National Strategy for Sustainable Development. In particular, and in line with the sustainable development strategy, specific actions are expected to define and evaluate policies, plans, programs, and projects for a full integration of sustainability targets. The Ministry recognized the importance of bioeconomy applied to the remediation of contaminated sites in the achievement of SDGs by funding the project BioGoal (Contaminated areas and circular bioeconomy: how to build regional strategies starting from sustainable development goals, personal communication) that looks at the Sicilian environment, economy, and society as a relevant study case for future replication.

\section{CONCLUSION}

Human activities are responsible for dramatic, extensive, and pervasive pollution worldwide as one of the environmental costs devoted to the unsustainable, great acceleration. While recognizing the prevention of pollution as a key priority, human society needs to make major efforts to prevent pollution and restore increasing portions of the territory through strategic and integrated policy approaches. At the global level, the importance of soil, land, and coastal zone management combined with human activities is increasingly stimulated by international political agenda through dedicated prevention, remediation, and restoration of contaminated sites at the regional, national, and EU levels. A systemic and harmonized implementation action is, however, still missing; to bridge this gap, we propose a cross-cutting approach, based on a comprehensive bioeconomy framework. Coordinated crosssectorial actions that include wide stakeholder participation could offer, through a bioeconomy approach, a new vision for an inclusive and sustainable growth. This will require the development of business models for the management of contaminated areas based on cutting-edge research and nature-based solutions that are developed in a strategic policy framework able to recognize the economic value of the reintegration of contaminated sites in a frame of regional development. The bioeconomy offers multiple benefits and frameworks for process implementation not only at regional scale but also up to European level. Positive feedback is expected by this approach, by promoting regenerative economies, 
with paramount benefits for the environment and human health. This would also make a step forward in the integration and alignment of policies by building favorable conditions based on the framework of the smart specialization strategy.

\section{AUTHOR CONTRIBUTIONS}

FF designed the structure and wrote the manuscript. FT checked the manuscript, proposed the comments, and revised the manuscript. MS checked and revised the manuscript. MZ and AB revised the manuscript. All the authors contributed to the article and approved the submitted version.

\section{REFERENCES}

A Bioeconomy for Europe (2012). Innovating for Sustainable Growth: A Bioeconomy. Luxembourg: Europe, EC, doi: 10.2777/6462

Bando SNSVS 2 (2019). Bando per la Promozione di Progetti di Ricerca a Supporto Dell'attuazione Della Strategia Nazionale per lo Sviluppo Sostenibile. Avaliable online at: https://www.minambiente.it/bandi/bando-promuovere- progetti-diricerca-supporto-dell-attuazione-della-strategia-nazionale-lo (accessed July $25,2020)$.

Bastioli, C. (2019). Bioeconomia Per la Rigenerazione Territoriale. Bologna BO: Alma Mater Studiorum Università di Bologna.

Bianconi, D., De Paolis, M. R., Agnello, A. C., Lippi, D., Pietrini, F., Zacchini, M., et al. (2011). "Field-scale rhyzoremediation of a contaminated soil with hexachlorocyclohexane $(\mathrm{HCH})$ isomers: the potential of poplars for environmental restoration and economical sustainability," in Handbook of Phytoremediation, ed. I. A. Golubev (Hauppauge, NY: Nova Science Publishers, Inc).

BioSTEP Consortium (2017). BioSTEP Policy Paper: Creating Networks for the Transition to a Bio-based and Circular Economy. Berlin: Ecologic Institute.

BIOVOICES Project (2018-2020). BIOVOICES Mobilization of a Plurality of Voices and Mutual Learning to Accelerate the Bio-Based Sector. The GRACE Project Has Received Funding From the Bio-Based Industries Joint Undertaking (BBI JU) under the European Union's Horizon 2020 Research and Innovation Programme Under Grant Agreement No 745012. Avaliable online at: https://www.biovoices. eu (accessed July 25, 2020).

BIT II (2019). Bioeconomy in Italy: A New Bioeconomy Strategy for a Sustainable Italy. Available online at: http://cnbbsv.palazzochigi.it/media/1774/bit_en_ 2019_02.pdf (accessed August 27, 2020).

Borja, A., Elliott, M., Uyarra, M. C., Carstensen, J., and Mea, M. (2017). Editorial: bridging the gap between policy and science in assessing the health status of marine ecosystems. Front. Mar. Sci. 4:32. doi: 10.3389/fmars.2017. 00032

Collet, I., and Engelbert, A. (2017). Coastal Regions: People Living Along the Coastline, Integration of NUTS 2010 and Latest Population grid. 2017. Luxembourg City: Eurostat. Statistics in focus 30/2013. ISSN:2314-9647 Catalogue number:KS-SF-13-030-EN-N.

COM 2007/575 (2007). Communication From the Commission to the European Parliament, the Council, the European Economic and Social Committee and the Committee of the Regions of 10 October 2007 on an Integrated Maritime Policy for the European Union; $\operatorname{COM(2007)} 575$ Final. Brussels: Commission of the European Communities.

COM 2013/659 (2013). A New EU Forest Strategy: For Forests and the ForestBased Sector, COM(2013) 659 final. Brussels: Commission of the European Communities.

COM 2016/0763 (2016). COM 2016/0763. Avaliable online at: https://eur-lex. europa.eu/legal-content/EN/TXT/HTML/?uri=CELEX:52016DC0763\&from= IT (accessed August 26, 2020).

Com 2019/640. (2019). The European Green Deal. Brussels: Commission of the European Communities.

\section{FUNDING}

This work was supported by CISAS (MIUR - Delibera CIPE n. 105/2015 del 23 dicembre 2015), BLUEMED CSA (Project H2020-EU.3.2.5; ID 727453), and MISTRAL (Interreg MED Project 4MED-123-009 nr.2925).

\section{ACKNOWLEDGMENTS}

We would like to thank the journal reviewers and in particular the editor Raul Perez Lejano for the thorough reviews, constructive criticisms, and comments which help to greatly improve the manuscript.

COM/2011/244 (2011). Communication From the Commission, Our Life Insurance, Our Natural Capital: An EU Biodiversity Strategy to 2020 \{COM/2011/244 final\}. Brussels: Commission of the European Communities.

Com/2012/046 (2012). Report from the Commission to the European Parliament, the Council, the European Economic and Social Committee and the Committee of the Regions the Implementation of the Soil Thematic Strategy and Ongoing Activities /* COM/2012/046 final */. Brussels: Commission of the European Communities.

COM/2013/216 (2013). An EU Strategy on Adaptation to Climate Change, Communication From the Commission $\{C O M / 2013 / 216$ final\}. Brussels: Commission of the European Communities.

COM/2017/0479 (2017). Commission Communication 'Investing in a Smart, Innovative and Sustainable Industry- A Renewed EU Industrial Policy Strategy' (COM/2017/0479 final). Brussels: Commission of the European Communities.

COM/2019/190 (2019). Report from the Commission to the European Parliament, the Council, the European Economic and Social Committee and the Committee of the Regions on the Implementation of the Circular Economy Action Plan COM/2019/190 Final. Brussels: Commission of the European Communities.

Costanza, R., de Groot, R., Braat, L., Kubiszewski, I., Fioramonti, L., Sutton, P., et al. (2017). Twenty years of ecosystem services: how far have we come and how far do we still need to go? Crawford School of Public Policy, Australian National. Ecosyst. Serv. 28, 1-16. doi: 10.1016/j.ecoser.2017.09.008

Council Directive 1999/31/EC (1999). On the landfill of waste. Luxembourg: EU Publications.

Council Directive 86/278/EEC (1986). On The Protection Of The Environment, And In Particular of The Soil, When Sewage Sludge Is Used In Agriculture. Luxembourg: EU Publications.

Council Directive 91/676/EEC (1991). 12 December 1991 Concerning the Protection of Waters Against Pollution Caused by Nitrates From Agricultural Sources. Luxembourg: : EU Publications.

Decree 46/19 (2019). Decreto 1 Marzo 2019, n. 46 . Regolamento Relativo agli Interventi di Bonifica, di Ripristino Ambientale $e$ di Messa in Sicurezza, D'emergenza, Operativa e Permanente, delle aree Destinate alla Produzione Agricola e all'allevamento, ai Sensi Dell'articolo 241 del Decreto Legislativo 3 Aprile 2006, n. 152. (19G00052). Avaliable online at: https: //www.gazzettaufficiale.it/eli/id/2019/06/07\%20/\%2019G00052\%20/\%20sg (accessed July 25, 2020).

Directive 2000/60/EC (2000). Of the European Parliament and of the Council of 23 October 2000 Establishing a Framework for Community Action in the Field of Water Policy. Luxembourg: EU Publications.

Directive 2004/35/CE (2004). Of the European Parliament and of the Council of 21 April 2004 on Environmental Liability With Regard to the Prevention and Remedying of Environmental Damage. Luxembourg: EU Publications.

Directive 2008/56/EC (2008). Of the European Parliament and of the Council of 17 June 2008 Establishing a Framework for Community Action in the Field of Marine Environmental Policy (Marine Strategy Framework Directive). Luxembourg: EU Publications. 
Directive 2008/98/EC (2008). On Waste and Repealing Certain Directives. Luxembourg: EU Publications.

Directive 2009/128/EC (2009). Of the European Parliament and of the Council of 21 October 2009 Establishing a Framework for Community Action to Achieve the Sustainable Use of Pesticides. Luxembourg: EU Publications.

Directive 2009/147/EC (2009). Of the European Parliament and of the Council of 30 November 2009 on the Conservation of Wild Birds. Luxembourg: EU Publications.

Directive 2009/28/EC (2009). On the Promotion of the Use of Energy From Renewable Sources and Amending and subsequently Repealing Directives 2001/77/EC and 2003/30/EC. Luxembourg: EU Publications.

Directive 2010/75/EU (2010). Of 24 November 2010 on Industrial Emissions (integrated Pollution Prevention and Control). Luxembourg: EU Publications.

Directive 2014/89/EU (2014). Of the European Parliament and of the Council of 23 July 2014 Establishing a Framework for Maritime Spatial Planning (MSMP). Luxembourg: EU Publications).

Directive 92/43/EEC (1992). Of 21 May 1992 on the Conservation of Natural Habitats and of Wild Fauna and Flora. Luxembourg: EU Publications.

Dubois, O., and Gomez San Juan, M. (2016). How Sustainability Is Addressed In Official Bioeconomy Strategies At International, National And Regional LevelS An overview. Rome: FAO.

Eea Report (2019). No 25/2018, Contaminants in Europe's Seas Moving towards a clean, Non-Toxic Marine Environment. Copenhagen: European Environment Agency, doi: 10.2800/511375

Final Report (2019). Final Report of the High-Level Panel of the European Decarbonisation Pathways Initiative. Brussels: European Commission, doi: 10. 2777/636

Fiorentino, N., Impagliazzo, A., Ventorino, V., Pepe, O., Piccolo, A., and Fagnano, M. (2010). Biomass accumulation and heavy metal uptake of giant reed on a polluted soil in Southern Italy. J. Biotechnol. 150(Suppl. 1):261. doi: 10.1016/j. jbiotec.2010.09.155

For a better innovation support to SMEs (2019). H2020 Programme 2018-2020; Innosup-01-2018-2020 Cluster Facilitated Projects for New Industrial Value Chains. Brussels: European Commission.

Frelih-Larsen, A., Bowyer, C., Albrecht, S., Keenleyside, C., Kemper, M., and Nanni, S. (2016). Updated Inventory and Assessment of Soil Protection Policy Instruments in EU Member States.' Final Report to DG Environment. Berlin: Ecologic Institute.

GRACE Project (2017-2022). GRowing Advanced industrial Crops on Marginal Lands for Biorefineries. Funded Under BBIJU Grant Agreement 745012. Avaliable online at: https://www.grace-bbi.eu.

Growth within (2015). A Circular Economy Vision for a Competitive Europe, Report by the Ellen MacArthur Foundation, the McKinsey Centre for Business and Environment and the Stiftungsfonds für Umweltökonomie und Nachhaltigkeit $(S U N)$. Cowes: Ellen Macarthur Foundation.

Hasenheit, M., Gerdes, H., Kiresiewa, Z., and Beekman, V. (2016). Summary report on the social, economic and environmental impacts of the bioeconomy. Available online at: http://www.bio-step.eu/fileadmin/BioSTEP/Bio_ documents/BioSTEP_D2.2_Impacts_of_the_bioeconomy.pdf (accessed August 26, 2020).

Horizon 2020 Work Programme 2018-2020 (2020). Food Security, Sustainable Agriculture and Forestry, Marine, Maritime and Inland Water Research and the Bioeconomy (European Commission Decision C(2020)1862 of 25 March 2020). Brussels: European Commission.

Jouffray, J. B., Blasiak, R., Norström, A. V., Österblom, H., and Nyström, M. (2020). The blue acceleration: the trajectory of human expansion into the ocean. One Earth 2, 45-54. doi: 10.1016/j.oneear.2019.12. 016

Lewandowski, I. (2018). Bioeconomy: Shaping the Transition to a Sustainable, Biobased Economy. Berlin: Springer International Publishing, doi: 10.1007/9783-319-68152-8

Lokesh, K., Ladu, L., and Summerton, L. (2018). Bridging the gaps for a 'Circular' bioeconomy: selection criteria, bio-based value chain and stakeholder mapping. Sustainability 10:1695. doi: 10.3390/su10061695
Lord, R. A., Atkinson, J., Scurlock, J. M. O., Lane, A. N., Rahman, P. K. S. M., Connolly, H. E., et al. (2008). "Biomass, remediation, re-generation (bioregen life project): reusing brownfield sites for renewable energy crops," in Paper presented at 15th European Biomass Conference Berlin. doi: 10.1061/40970 (309)66

Payá Pérez, A., and Rodríguez Eugenio, N. (2017). Status of Local Soil Contamination in Europe: Revision of the Indicator "Progress in the Management Contaminated Sites in Europe, 2017. Luxembourg: Publications Office of the European Union, doi: 10.2760/093804, JRC107508 EUR $29124 \mathrm{EN}$.

Pietrini, F., Iori, V., Pietrosanti, L., Passatore, L., Zuin, M. C., Aromolo, R., et al. (2018). "A Survey on the Metal(loid) accumulation ability of spontaneous and established plants for the phytomanagement of an industrial landfill in the venice lagoon," in Phytoremediation: Management of Environmental Contaminants, Vol. 6, eds A. A. Ansari, S. S. Gill, R. Gill, G. R. Lanza, and L. Newman (Switzerland: ๑ Springer International Publishing), 113-131. doi: 10.1007/978-3-319-99651-6_4

Pietrini, F., Passatore, L., Patti, V., Francocci, F., Giovannozzi, A., and Zacchini, M. (2019). Morpho-physiological and metal accumulation responses of hemp Plants (Cannabis Sativa L.) grown on soil from an agro-industrial contaminated area. Water 11:808.

Reg (UE) N. 1305/2013 (2013). PSR 2014/2020 DEL LAZIO. MISURA 16 "COOPERAZIONE". SOTTOMISURA 16.1 "Sostegno per la costituzione e la gestione dei Gruppi Operativi del PEI in Materia di Produttività e Sostenibilità Dell'agricoltura". Domanda Ammessa Codice 54250701718 Biosaccovalley: Salvaguardia Della Biodiversità e Promozione Della Filiera Fitorimedio per il Rilancio della Valle del Sacco.

Regional Biotechnology (2011). Establishing a Methodology and Performance Indicators for Assessing Bio-Cluster and Bio-Regions Relevant to the KBBE Area $(P w C, 2011)$. Avaliable online at: https://www.pwc.de/de/offentlicheunternehmen/assets/neues-denken/regional-biotech-report.pdf (accessed July $25,2020)$.

Regulation (EC) No 1907/2006 (2006). Of the European Parliament and of the Council on the Registration, Evaluation, Authorisation and Restriction of Chemicals (REACH). Brussels: European Union.

REMEDIA Project (2017-2021). REmediation of Marine Environment and Development of Innovative Aquaculture: Exploitation of Edible/not Edible Biomass; LIFE16 ENV/IT/000343. Eisenstadt: REMEDIA.

Ronzon, T., and M'Barek, R. (2018). Socioeconomic indicators to monitor the EU's bioeconomy in transition. Sustainability 10:1745. doi: 10.3390/su10061745

SABANA Project (2016-2021). SABANA Sustainable Algae Biorefinery for Agriculture aNd Aquaculture. Horizon 2020 Research and Innovation program under the Grant Agreement No. 727874. Avaliable online at: http://www.eusabana.eu

Sotenko, M., Coles, S., Barker, G., Song, L., Jiang, Y., Longhurst, P., et al. (2017). Phytoremediation-biorefinery tandem for effective clean-up of metal contaminated soil and biomass valorisation. Int. J. Phytoremediation. 19, 965975. doi: $10.1080 / 15226514.2016 .1267705$

Spatial Foresight (2017). SWECO, ÖIR, t33, Nordregio, Berman Group, Infyde (2017): Bioeconomy Development in EU Regions. Mapping of EU Member States'/regions' Research and Innovation Plans \& Strategies for Smart Specialisation (RIS3) on Bioeconomy for 2014-2020. Brussels: European Commission.

State of the Union (2018). Letter of Intent to President Antonio Tajani and to Chancellor Sebastian Kurz. Avaliable online at: https:/ec.europa.eu/ commission/sites/beta-political/files/soteu2018-letter-of-intent_en.pdf (accessed July 25, 2020).

Steffen, W., Broadgate, W., Deutsch, L., Gaffney, O., and Ludwig, C. (2015). The trajectory of the anthropocene: the great acceleration. Anthropoc. Rev. 2, 81-98. doi: $10.1177 / 2053019614564785$

SuperBIO (2016-2019). Is Funded by the Research and Innovation Programme 'Horizon 2020' of the European Union under the Grant Agreement no. 691555 for the Period 01.06.2016 to 30.11.2018. Available online at: http://www.h2020-superbio.eu/value-chains (accessed July 25, 2020). 
SWD 2017/128 (2017). EC (2017) Report on the Blue Growth Strategy Towards More Sustainable Growth and Jobs in the Blue Economy (SWD 2017/ 128 final). Brussels: European Commission.

UNEP (2018). 'What are POPs?', Stockholm Convention. Nairob: UNEP.

United Nations (2015). Transforming Our World: The 2030 Agenda for Sustainable Development A/RES/70/1. New York, NY: United Nations.

Updated Bioeconomy Strategy (2018). A Sustainable Bioeconomy for Europe: Strengthening the Connection Between Economy, Society and the Environment. Brussels: European Commission. doi: 10.2777/792 130
Conflict of Interest: The authors declare that the research was conducted in the absence of any commercial or financial relationships that could be construed as a potential conflict of interest.

Copyright (๑) 2020 Francocci, Trincardi, Barbanti, Zacchini and Sprovieri. This is an open-access article distributed under the terms of the Creative Commons Attribution License (CC BY). The use, distribution or reproduction in other forums is permitted, provided the original author(s) and the copyright owner(s) are credited and that the original publication in this journal is cited, in accordance with accepted academic practice. No use, distribution or reproduction is permitted which does not comply with these terms. 